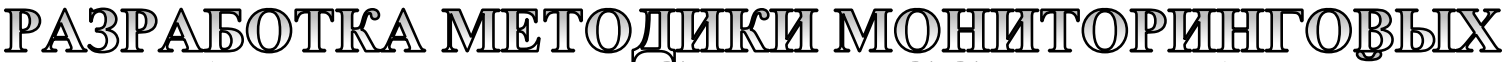

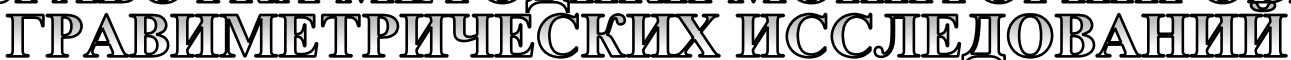

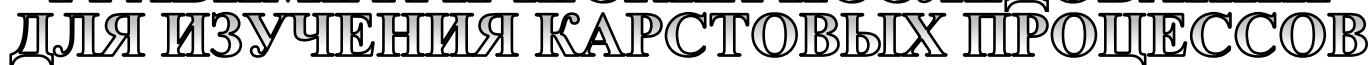

\author{
А.А. Симанов, Горный институт УрО РАН \\ В.В. Хохлова, Горныцй институт УрО РАН
}

\section{Для цитирования:}

Симанов А.А., Хохлова В.В. Разработка методики мониторинговых гравиметрических исследований для изучения карстовых процессов // Вестник Пермского федерального исследовательского центра. - 2021. - № 3. - С. 34-41. https://doi.org/10.7242/2658-705X/2021.3.5

При поддержке проекта регионального конкурса РФФИ в 2017-2019 гг. разработана принципиально новая методика мониторинговых гравиметрических наблюдений, включающая в себя динамическую составляющую, т.е. изменение параметров поля во времени. Предлагаемые методы являются опережающими в том смысле, что предназначены для оперативного картирования карста в плане, приблизительной оценки его фризических и геометрических параметров. Работы были проведены для опробования различных вариантов методики полевых работ на конкретных геологических объектах.

Создана геологическая модель гравиметрического мониторинга карстового процесса и доказано, что с использованием разработанной методики и современной геофизической аппаратуры можно определить начало процесса разуплотнения пород, выявляя зоны последующих возможных оседаний и провалов земной поверхности. Основываясь на геологической модели гравиметрического мониторинга, разработана методика интерпретации динамических аномалий силы тяжести, на базе которой создана технология количественной интерпретации выделенных динамических аномалий гравитационного поля. Интерпретация динамических аномалий силы тяжести основана на совместном применении качественных и количественных методов извлечения геологической информации из гравиметрических данных.

Решение обратных задач предлагается осуществлять монтажным методом с использованием гарантированного подхода к оценке качества решения обратной задачи и с построением фуннкции локализации источников поля. Модель среды, используемая при этом методе решения задачи (изолированный объект в однородной среде), полностью удовлетворяет геологической модели гравиметрического мониторинга, поскольку влияние неизменных плотностных неоднородностей в массиве, обусловленных геологическим строением, отсутствует в динамических аномалиях силы 
тяжести. Результатом количественной интерпретации динамических аномалий является вероятный интервал глубин изменения массы (объема) горных пород, произошедший между двумя парами измерений поля.

Ключевые слова: гравиразведка, мониторинг, аномалия гравитационного поля, динамическая гравитачионная аномалия, геологическая модель, интерпретация, карст, обратные задачи.

В рамках фундаментальной проблемы обеспечения безопасности рудников, шахт, жизнедеятельности населения разработана методика и программно-алгоритмический аппарат обработки и интерпретации мониторинговых гравиметрических наблюдений, которые направлены на выявление карстовых областей в массиве, а также выполнена апробация комплекса опережающих геофизических работ, с целью обнаружения участков с интенсивным развитием карстовых процессов.

Анализ зарубежных и российских публикаций показал, что гравиметрические данные используются только для изучения соляных куполов и диапиров $[2,26]$. Мониторинговые гравиметрические наблюдения выполняются, как правило, для изучения вулканов, грунтовых вод и месторождений углеводородов [1, 18, 22, 27, 28].

За период работы 2017-2019 гг. авторами проекта выполнены опытно-методические геофизические работы, в состав которых входили высокоточные гравиметрические наблюдения на территории Верхнекамского месторождения калийных солей. Данные работы были проведены для опробования различных вариантов методики полевых работ на конкретных геологических объектах. На основе полученных данных выделены участки с интенсивным развитием карстово-суффозионных процессов. Получены сведения о плотностных характеристиках горных пород верхней части разреза. По результатам повторных наблюдений была рассчитана динамическая аномалия силы тяжести, определяемая как разность между последующими и предыдущими значениями силы тяжести. Поскольку все неизменные составляющие гравитационного поля в равной степени присутствуют в любой паре наблю- дений, динамическая аномалия отражает только конкретный горнотехнический или быстротекущий геологический процесс.

Проблема изучения горного массива, расположенного над естественными или техногенными полостями в геологическом пространстве существует уже давно. К естественным полостям относятся пещеры, доступные для проникновения, к техногенным - горные выработки шахтного производства, а также подземные коммуникационные сети на урбанизированных территориях. От сохранности массива горных пород над этими полостями часто зависит безопасность жизнедеятельности населения, сохранность самого рудника или природного объекта. Изучение территории с поверхности посредством геофизических наблюдений даёт хорошие результаты как с точки зрения выявления ослабленных или потенциально опасных зон (при однократно проведенной съемке), так и в плане прогноза развития аномальных зон в пространстве с течением времени (в случае регулярных повторных наблюдений).

Для изучения и прогнозирования негативных инженерно-геологических явлений широко используются геофизические методы, немаловажную роль в комплексе которых играют гравиметрические исследования. Актуальностью проблемы является развитие теории интерпретации геопотенциальных полей в трехмерном пространстве, которая, прежде всего, включает анализ мониторинговых гравиметрических наблюдений, разделения по глубине источников аномалий в трехмерном пространстве, решение обратных задач с целью получения единой плотностной картины недр, определение глубинной приуроченности областей интенсивного развития карста. 
Области с интенсивным развитием карстовых процессов в горном массиве отчетливо фиксируются в динамическом гравитационном поле. Созданная методика мониторинговых наблюдений, проведенных в различные периоды времени, позволяет локализовать области интенсивного развития карстовых процессов, существенно повысить разрешающую способность и достоверность выделения аномалий, при этом снизится неоднозначность решения обратных задач гравиметрии в линейной и нелинейной постановке [6-10].

В период проведения проекта создана геологическая модель гравиметрического мониторинга карстового процесса и доказано, что с использованием разработанной методики и современной геофизической аппаратуры можно определить начало процесса разуплотнения пород, выявляя зоны последующих возможных оседаний и провалов земной поверхности.

Геологическая модель гравиметрического мониторинга карстового процесса представляет собой изолированную область, где произошли изменения плотности пород, в однородной геологической среде (рис. 1) [6-10]. Экстремальные величины гравитационных эффектов в зависимости от глубины зоны разуплотнения $(H)$ и ее размеров $(R)$ приведены изолиниями на рис. $1, \sigma$, оцифрованными в миллигалах. Следует отметить, что данные эффек-

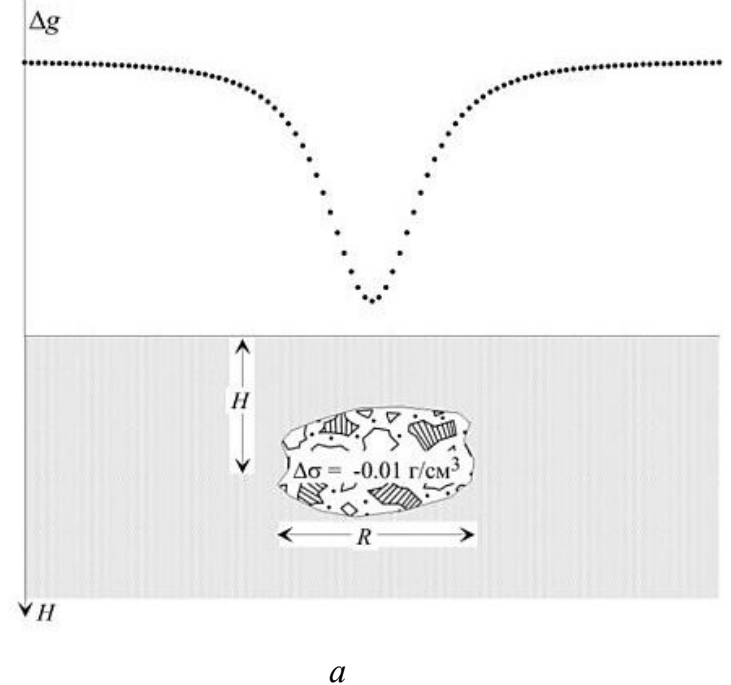

ты вычислены при изменении плотности геологического объекта на $0,01 \Gamma / \mathrm{cm}^{3}$, которая очень мала и находится в пределах точности денситометрии. Учитывая, что современная гравиметрическая и геодезическая аппаратура позволяет зафиксировать аномалии силы тяжести с точностью $\pm 0,005-0,007$ мГал, по гравиметрическим данным можно определить начало процесса разуплотнения пород, выявляя зоны последующих возможных оседаний и провалов земной поверхности.

Интерпретация динамических аномалий силы тяжести осуществляется на основе совместного применения качественных и количественных методов извлечения геологической информации из гравиметрических данных. На начальной стадии интерпретационного процесса используется система VECTOR [18], с помощью которой строится изображение геологической среды - пространственное распределение квазиплотности, отражающее некоторые элементы физико-геологической модели (рис. 2,a). Параметр квазиплотности не имеет размерности физического параметра плотности, а шкала глубин построенных разрезов и 3D-диаграмм не отвечает истинной. Однако результаты векторного сканирования успешно используются для уточнения геологических гипотез и задания априорных ограничений при последующем решении обратной задачи.

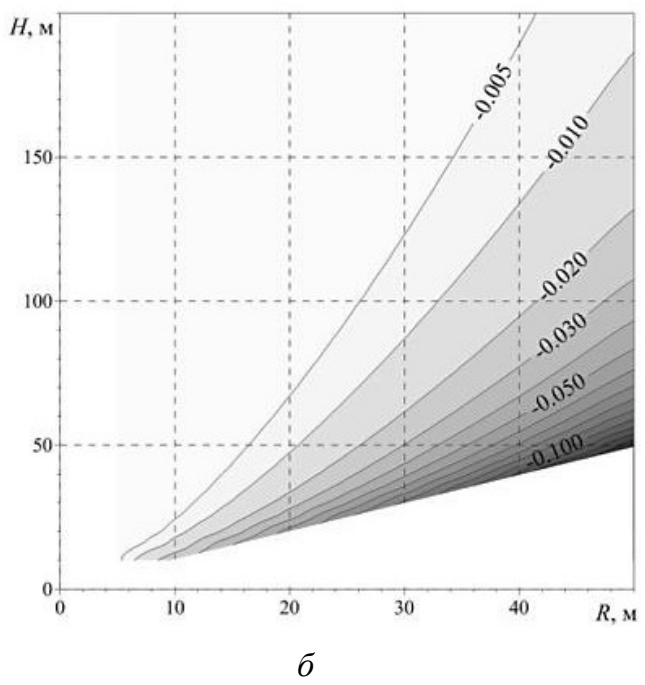

Рис. 1. а-геологическая модель гравиметрического мониторинга; б-гравитационные эффекты модели 


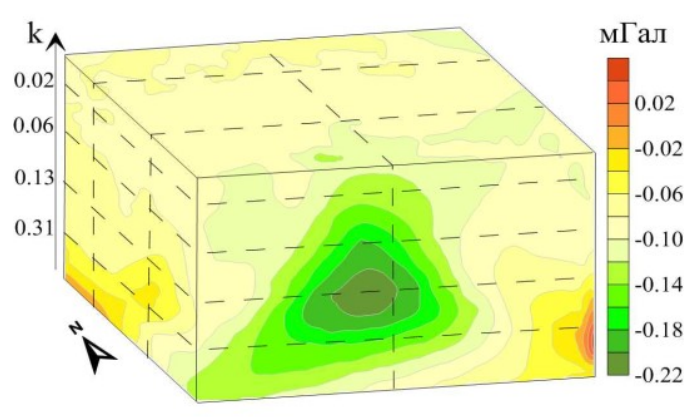

$a$

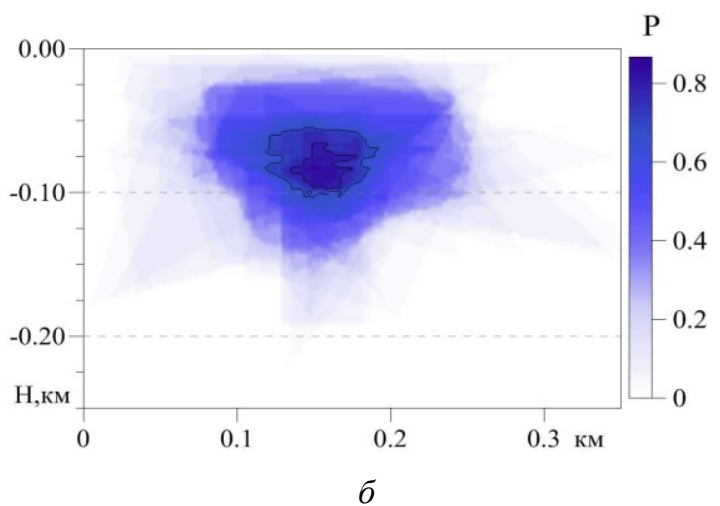

Puc. 2. а-выделение локальной динамической аномалии силь тяжести в системе VECTOR; б-результат решения нелинейной обратной задачи

Решение обратных задач предлагается осуществлять монтажным методом с использованием гарантированного подхода к оценке качества решения обратной задачи и с построением функции локализации источников поля. Модель среды, используемая при этом методе решения задачи (изолированный объект в однородной среде), полностью удовлетворяет геологической модели гравиметрического мониторинга, поскольку влияние неизменных плотностных неоднородностей в массиве, обусловленных геологическим строением, отсутствует в динамических аномалиях силы тяжести $[16,17]$. Результатом количественной интерпретации динамических аномалий является вероятный интервал глубин изменения массы (объема) горных пород, произошедший между двумя парами измерений поля (рис. 2, б). На одном из потенциально опасных участков на территории г. Березники в 2016 г. были начаты работы, где выполнено семь циклов мониторинговых гравиметрических работ. Здесь создан гравиметрический полигон, состоящий из 102 пунктов, работы на котором выполняются на закрепленных металлических знаках (дюбелях, забитых в асфальт) гравиметрами AUTOGRAV CG-5.

На первом этапе проводили гравиметрические и геодезические наблюдения между гравиметрическим пунктом 1-го разряда и опорным гравиметрическим пунктом 3-го класса, который расположен вне зоны влияния инженерно-геологических, горнотехнических и геодинамических процессов.
На втором этапе проводили гравиметрические и геодезические измерения на пунктах временной опорной сети. Определение силы тяжести на всех опорных пунктах рассчитывалось по результатам 2-3 независимых рейсов двумя гравиметрами. Создание временной опорной сети позволило сократить длительность гравиметрических рейсов и тем самым повысить точность наблюдений на пунктах мониторинговых наблюдений.

Третий этап заключался в гравиметрических и геодезических наблюдениях на рядовых пунктах мониторинговых наблюдений. На каждом гравиметрическом пункте выполнялось по три цикла наблюдений продолжительностью от 30 до 60 секунд каждый. Измерения на пунктах рядовой сети производились по однократной методике со $100 \%$ повторением двумя гравиметрами. Среднеквадратическая погрешность определения силы тяжести составляла при этом 0,0050,007 мГал, точность определения высот на закрепленных пунктах 1-2 см.

Полевая обработка получаемых результатов измерений включала ежедневный анализ показаний гравиметров в каждом отдельном рейсе; анализ характера сползания нуль-пункта; отбраковку значений по результатам анализа показаний обработки и принятие решения о необходимости повторения измерений на пункте; оценку величин поправок значений силы тяжести на данном пункте по данным геодезических наблюдений (сохранность планового и высотно- 
го положения точки наблюдения); сопоставление показаний гравиметра при повторных и контрольных измерениях.

По результатам мониторинговых наблюдений в 2016-2017 гг. выявлена отрицательная динамическая аномалия, которая может быть связана с процессами разуплотнения пород и возможными местами оседаний земной поверхности (рис. 3). По результатам количественной интерпретации выделенной аномалии размер зоны разуплотнения может достигать более 200 м в плане и мощности 20-40 м, плот-

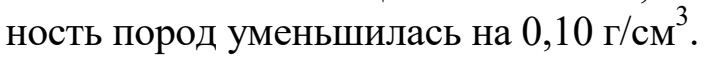

Дальнейшие гравиметрические наблюдения показали, что амплитуда и размеры динамической аномалии существенным образом меняются в различных циклах мониторинга, при этом происходят неравномерные оседания земной поверхности (рис. 4). Участки повышенных оседаний земной поверхности сопровождаются уменьшением величины динамической аномалии, что объясняется компенсацией значений аномалий уменьшением высот пунктов и увеличением плотности пород.

На рис. 4 приведены карты изменения силы тяжести за разные годы измерений на фоне городской застройки. Анализируя карты динамических аномалий в раз-

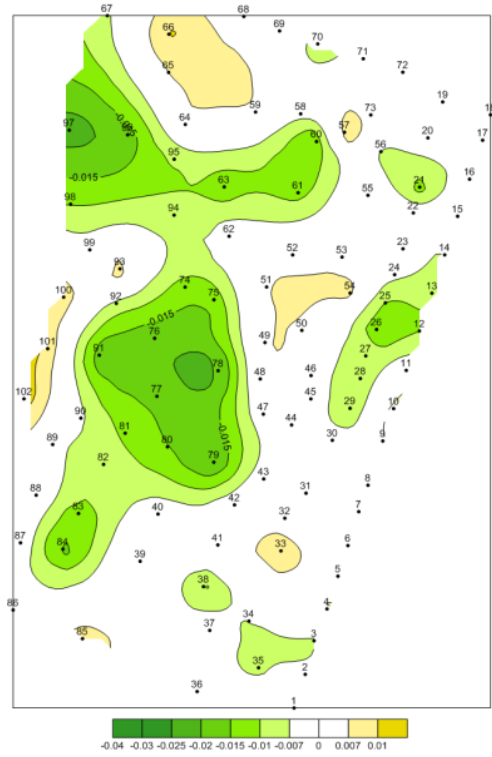

$a$ ные периоды времени, прежде всего, можно отметить, что амплитуда, размеры и местоположение динамических аномалий существенным образом меняются в различных циклах мониторинга.

Можно констатировать увеличение скорости изменения силы тяжести: если в первый период (2016-2017 гг.) амплитуда отрицательной аномалий составляла $-0,04$ мГал (рис. $4 a$ ), то за последний год (2018-2019 гг.) амплитуда увеличилась до -0,10 мГал (рис. 4 в). Количественная интерпретация динамических аномалий показала, что источник изменения поля находится на глубине порядка 20-40 м, плотность его изменилась на $-0,1$ г/ $\mathrm{cm}^{3}$. Увеличение амплитуды динамической аномалии свидетельствует об ускорении процесса разуплотнения пород надсоляной толщи, расположенной над затопленными шахтными полями, что в дальнейшем может привести к провалам земной поверхности на данной территории.

Изменение формы динамических аномалий в пространстве, по нашему мнению, связано с процессом непрерывного оседания земной поверхности. Участки повышенных оседаний сопровождаются уменьшением величины динамической аномалии, что объясняется компенсацией значений аномалий увеличением плотности пород, обусловленной оседанием, и уменьшением высот пунктов. Например, в 2018 г. наиболее интенсивные динамические аномалии силы тяжести проявлялись

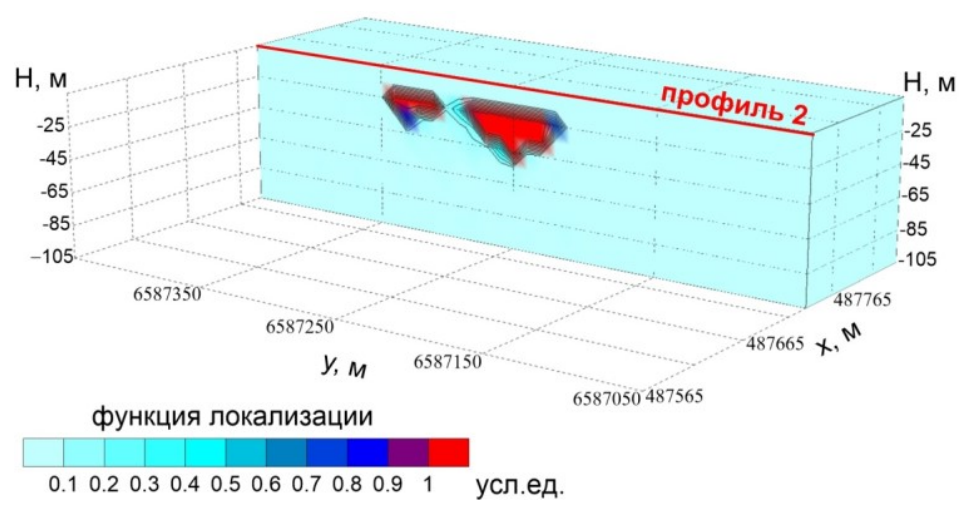

$\sigma$

Рис. 3. Результаты гравиметрического мониторинга: a - карта динамических аномалий (сентябрь - декабрь 2016 г.); б - вертикальное сечение функиии локализации источников аномалий 


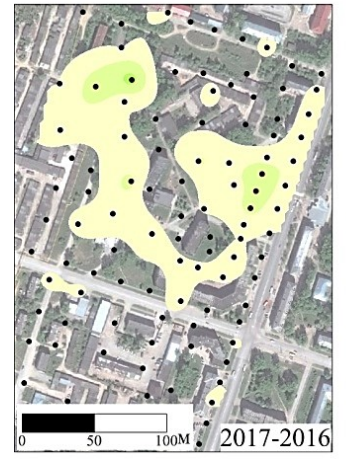

$a$

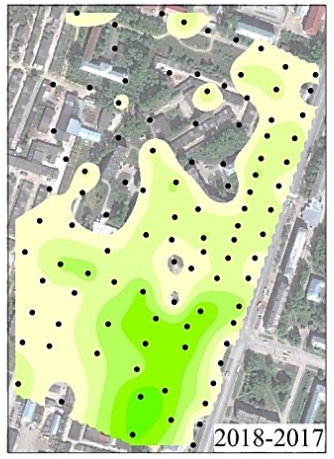

6

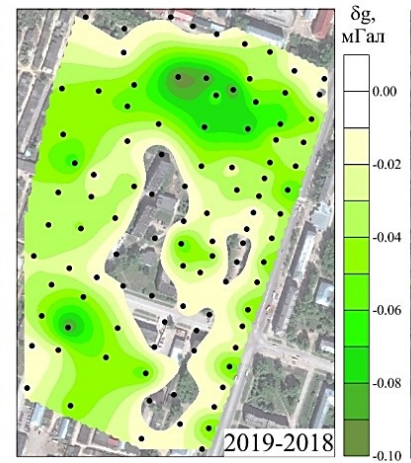

B

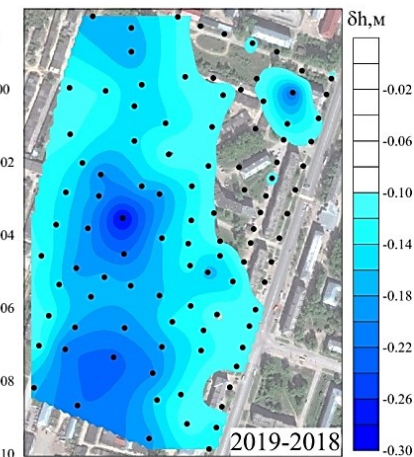

2

Рис. 4. Карты динамических аномалий: $а$-сентябрь 2016 г.-сентябрь 2017 г.,

б - сентябрь 2017 г. - ноябрь 2018 г., в - ноябрь 2018 г. - сентябрь 2019 г.,

г-оседания земной поверхности в период с ноября 2018 г. по сентябрь 2019 г.

(черными точками показаны пункты гравиметрических наблюдений)

на юге участка (рис. 4, в), в 2018-2019 гг. здесь произошли повышенные оседания земной поверхности до $30 \mathrm{~cm}$ (рис. 4, г), что подтвердило сделанный нами ранее прогноз оседаний. Одновременно с оседанием в этой части участка произошло «затухание» динамической аномалии (рис. 4, в). За период 2018-2019 гг. наиболее интенсивные динамические аномалии сместились на юг и запад участка (рис. 4, в). Вероятно, здесь в дальнейшем следует ожидать повышенные оседания земной поверхности.

\section{Заключение}

Эксперименты показали, что с помощью указанного комплекса успешно решается задача картирования карстовых полостей и разрывных нарушений, а также появляется возможность определить временные трансформации модели и оценить степень опасности состояния водозащитной толщи для эксплуатации месторождений. Изменения плотности пород в горном массиве, происходящие под влиянием горно-геологических условий, отчетливо фиксируются в гравитационном поле.

Разработанная технология проведения и интерпретации мониторинговых гравиметрических наблюдений позволяет перейти на новый качественный уровень получения информации о распределении и развитии во времени плотностных неоднородностей геологического разреза, что существенно повышает безопасность проведения горных работ. Гравиметрия должна применяться как опережающий метод, позволяющий на предварительном этапе уточнить геолого-тектоническую обстановку в пределах шахтных полей, выделить зоны повышенного риска.

В более широком рассмотрении результаты работ являются примером широкой апробации методики опережающего исследования, направленной на прогнозирование разрушительных последствий карстово-суффозионных процессов.

\section{Библиографический список}

1. Андреев О.П., Кобылкин Д.Н., Ахмедсафин С.К., Кирсанов С.А., Безматерных Е.Ф., КривицкийГ.Е. Гравиметрический контроль разработки газовых и газоконденсатных месторождений. Состояние, проблемы, перспективы. - М.: ООО Издательский дом Недра. 2012. - 374 c.

2. Багрій С.М., Кузьменко Е.Д., Анікеєв С.Г. Оцінка ступеня просідання земної поверхні на шахтних полях Калуського гірничо-промислового району за даними високоточної гравіметрії // Научные труды SWorld. - 2016. - №1 (42). - C. 40-48.

3. Бычков С.Г. Гравиметрический мониторинг: возможности, задачи, перспективы // Стратегия и процессы освоения георесурсов: Сб. науч. тр., вып. 15. - Пермь, ГИ УрО РАН, - 2017. - С. 146-149.

4. Бычков С.Г., Долгаль А.С., Костищьын В.И., Симанов А.А., Хохлова В.В. Редуцирование высокоточных гравиметрических наблюдений // Геодезия, картография, кадастр, ГИС - 
проблемы и перспективы развития: тез. докл. Международной науч.-техн. кон / Полоцкий гос. ун-т. - Новополоцк: ПГУ, 2016. - С. 26-30.

5. Бычков С.Г., Долгаль А.С., Симанов А.А., Хохлова В.В. Опыт использования современных процедур обработки высокоточных гравиметрических съемок // Интерэкспо ГЕО-Сибирь-2017. XIII Междунар. науч. конгр. (17-21 апреля 2017 г.). Междунар. науч. конф. «Недропользование. Горное дело. Направления и технологии поиска, разведки и разработки месторождений полезных ископаемых. Экономика. Геоэкология». - Т. 3. - Новосибирск: СГУГиТ, 2017. - С. 99-104.

6. Бычков С.Г., Мичурин А.В., Симанов А.А. Гравиметрический мониторинг аварийных участков рудников Верхнекамского месторождения калийных солей // Материалы 44-й сессии Междунар. науч. семинара им. Д.Г.Успенского «Вопросы теории и практики геологической интерпретации геофизических полей» - М.: ИФЗ РАН, 2017. - С. 75-79.

7. Бычков С.Г., Мичурин А.В., Симанов А.А. Гравиметрический мониторинг аварийных участков рудников Верхнекамского месторождения калийных солей // Геология и полезные ископаемые Западного Урала: сборник статей по материалам Всерос. науч.-практ. конф. с междунар. участием. - Пермь, ПГНИУ, 2017. - С. 132-137.

8. Бычков С.Г., Мичурин А.В., Симанов А.А. Гравиметрический мониторинг карстовых процессов // Глубинное строение, геодинамика, тепловое поле Земли, интерпретация геофизических полей: Девятые научные чтения памяти Ю.П. Булашевича. - Екатеринбург, ИГф УрО РАН. 2017. - C. 93-97.

9. Бычков С.Г., Мичурин А.В., Симанов А.А. Гравиметрический мониторинг рудников Верхнекамского месторождения калийных солей // Геофизика. - 2017. - № 5. - С. 10-16.

10. Бычков С.Г., Мичурин А.В., Симанов А.А. Результаты гравиметрического мониторинга аварийных участков рудников Верхнекамского месторождения калийных солей // Вопросы теории и практики геологической интерпретации геофизических полей: Материалы 45-й сессии Междунар. семинара им. Д.Г.Успенского. - Казань: Казанский ун-т. 2018. - С. 130-131.

11. Бычков С.Г., Простолупов Г.В., Симанов А.А., Щербинина Г.П. Гравиметрические исследования аварийных участков рудников Верхнекамского месторождения калийных солей // Геология и полезные ископаемые Западного Урала: сб. ст. юбилейной конф., посвящ. 100летию Пермского ун-та и 85-летию геол.ф-та. ПГНИУ. - Пермь, 2016. - С. 124-127.

12. Бычков С.Г., Простолупов Г.В., Щербинина Г.П. Наземно-подземная гравиразведка на Верхнекамском месторождении калийных солей // Теория и практика разведочной и промысловой геофизики: Материалы Междунар. науч.-практ. конф. - Пермь, 2016. - С. 76-80.

13. Бычков С.Г., Простолупов Г.В., Щербинина Г.П. Прикладные задачи гравиметрии при обеспечении безопасности отработки месторождения растворимых солей // Геофизика. - 2018. № 5. - C. 4-12.

14. Бычков С.Г., Простолупов Г.В., Щербинина Г.П. Применение наземно-подземной гравиразведки на Верхнекамском месторождении калийных солей // Геофизика. - 2016. - № 5. - С. 37-41.

15. Бычков С.Г., Симанов А.А. Возможная природа повышенной дисперсии отсчетов гравиметра // Геология и полезные ископаемые Западного Урала. Вып. 1(38). - Пермь: ПГНИУ, 2018. - С. 163-167.

16. Мичурин А.В. Комплексная интерпретация геофизических данных при поисках меднопорфирового оруденения // Стратегия и процессы освоения георесурсов. Вып. 16. - Пермь: ГИ УрО РАН, -2018 . - С. 150-152.

17. Мичурин А.В. Решение линейной обратной задачи гравиразведки по площадным измерениям методом минимизации эмпирического риска // Стратегия и процессы освоения георесурсов: Сб. научн. Трудов. Вып. 14. - Пермь: ГИ УрО РАН, - 2016. - С. 147-149.

18. Простолупов Г.В., Новоселицкий В.М., Конешов В.Н., Щербинина Г.П. Об интерпретации гравитационного и магнитного полей на основе трансформации горизонтальных градиентов в системе «VECTOR» // Физика Земли. - 2006. - № 6. - С. 90-96.

19. Симанов А.А. Гравиметрический мониторинг карстово-суффозионных процессов в районах интенсивного освоения недр // Стратегия и процессы освоения георесурсов. Вып. 16. - Пермь: ГИ УрО РАН, - 2018. - С. 161-163.

20. Симанов A.A. Опытные геофизические работы на территории историко-природного комплекса «Ледяная гора и Кунгурская ледяная пещера» // Стратегия и процессы освоения георесурсов: Сб. научн. трудов. Вып. 14. - Пермь: ГИ УрО РАН, - 2016. - С. 160-162.

21. Хохлова В.В. Вычисление гравитационных эффектов в сферической системе координат // Стратегия и процессы освоения георесурсов: Сб. научн. трудов. Вып. 14. - Пермь: ГИ УрО PAH, - 2016. - C. 166-168. 
22. Branston M.W., Styles P. The Use of Time-Lapse Microgravity to Investigate and Monitor an Area Undergoing Surface Subsidence; A Case Study // Symposium on the Application of Geophysics to Engineering and Environmental Problems - 2002. P. CAV10-CAV10.

23. Bychkov $S$. The tomographic transform of the gravity field and their geological interpretation // 8th Saint Petersburg International Conference \& Exhibition «Saint Petersburg 2018. Innovations in Geosciences Time for Breakthrough»-Saint Petersburg, Russia (9-12 April 2018). Submission ID: 44418. 6 p.

24. Bychkov S., Michurin A., Simanov A. Interpretation of results gravity monitoring of karst processes // 8th Saint Petersburg International Conference \& Exhibition «Saint Petersburg 2018. Innovations in Geosciences - Time for Breakthrough» - Saint Petersburg, Russia (9-12 April 2018). Submission ID: 44417. 6 p.

25. Bychkov S.G., Michurin A.V., Simanov A.A. Gravimetric monitoring of technogenic impact on geological environment // Engineering and Mining Geophysics. 2018 (23-27 April 2018), - Almaty, Kazakhstan. Submission ID: 46144. 6 p.

26. Davis K., Li Y., Batzle M. Time-lapse gravity monitoring: A systematic 4D approach with application to aquifer storage and recovery // Geophysics. - 2008. - Vol. 73. - № 6. - P. WA61-WA69.

27. Gasperikova E., Hoversten G.M. Gravity monitoring of $\mathrm{CO} 2$ movement during sequestration: Model studies // Geophysics. - 2008. - Vol. 73. - № 6. - P. WA105-WA112.

28. Kennedy J., Ferre T.P., Guntner A., Abe M., Creutzfeldt B. Direct measurement of subsurface mass change using the variable baseline gravity gradient method // Geophysical Research Letters. - 2014. Vol. 41. - P. 2827-2834.

\title{
DEVELOPMENT OF MONITORING GRAVIMETRIC SURVEY METHOD FOR STUDYING KARST PROCESSES
}

\author{
A.A. Simanov, V.V. Khokhlova
}

Mining Institute UB RAS

\section{For citation:}

Simanov A.A., Khokhlova V.V. Development of monitoring gravimetric survey method for studying karst processes // Perm Federal Research Center Journal. - 2021 - № 3. - P. 34-41. https://doi.org/10.7242/2658-705X/2021.3.5

Within the framework of solving the fundamental issue of ensuring the safety of mining camps, mines, and vital functioning of the population, a methodology and a software algorithmic apparatus have been developed for processing and interpreting monitoring gravimetric observations which are aimed at identifying karst areas in the massif. A complex of prospective geophysical works aimed at detecting areas with intensive development of karst processes has been tested. The authors of the project carried out experimental methodological geophysical works including high-precision gravimetric observations on the territory of the Verkhnekamskoye potash deposit. These works were carried out to test various options for the field work methodology on specific geological objects. In a broader sence, the results of the work are an example of a wide approbation of an advanced research methodology aimed at predicting the destructive consequences of karst-suffusion processes.

Keywords: gravity, monitoring, anomaly of the gravity field, dynamic gravity anomaly, geological model, interpretation, karst.

\section{Сведения об авторах}

Симанов Алексей Аркадьевич, кандидат технических наук, научный сотрудник, Горный институт УрО РАН - филиал Пермского федерального исследовательского центра УрО РАН («ГИ УрО РАН»), 614007, г. Пермь, ул. Сибирская, 78А; e-mail: simanov@mi-perm.ru

Хохлова Валерия Васильевна, младший научный сотрудник, «ГИ УрО РАН»; e-mail: valxov@yandex.ru 